\title{
Facile synthesis of functionalized tetrahydroquino- lines via domino Povarov reactions of arylamines, methyl propiolate and aromatic aldehydes
}

\author{
Jing Sun, Hong Gao, Qun Wu and Chao-Guo Yan*
}

Open Access

\author{
Beilstein J. Org. Chem. 2012, 8, 1839-1843. \\ doi:10.3762/bjoc.8.211 \\ Received: 16 August 2012 \\ Accepted: 24 September 2012 \\ Published: 26 October 2012 \\ Associate Editor: J. P. Wolfe \\ (c) 2012 Sun et al; licensee Beilstein-Institut. \\ License and terms: see end of document.
}

\begin{abstract}
In the presence of $p$-toluenesulfonic acid as catalyst the domino reaction of arylamines, methyl propiolates and aromatic aldehydes in ethanol proceeded smoothly to give polysubstituted 1,2,3,4-tetrahydroquinolines in moderate yields. The reaction is believed to involve the Povarov reaction of in situ generated $\beta$-enamino ester with the in situ formed aromatic imine.
\end{abstract}

\section{Introduction}

The Diels-Alder reaction is recognized as a powerful reaction in synthetic strategies for the production of natural and unnatural polycarbocycles and polyheterocycles [1-3]. Therefore, the hetero-Diels-Alder reactions and domino reaction procedures have been developed as the most powerful synthetic routes to construct oxygen or nitrogen-containing six-membered heterocycles [4-8]. In recent years, the imine Diels-Alder reaction (also known as Povarov reaction) and the $[4+2]$ cycloaddition reaction of imines (obtained from the corresponding aromatic aldehyde and aniline derivatives) with alkenes have become efficient strategies for the generation of $N$-heterocycles [9-11]. In these reactions the alkene must be electron-rich, which means that functional groups attached to the alkene should be able to donate electrons. Among the electron-rich dienophiles, vinyl enol ethers, vinyl enamides, vinyl sulfides, cyclopentadienes, indenes, alkynes and enamines have been mostly used in this method [12-22]. $\beta$-Enamino esters [23-26], which may be readily generated in situ by the addition of a primary amine to electron-deficient alkynes, such as methyl propiolate or dimethyl acetylenedicarboxylate [27-30], have shown versatile reactivity and have been widely used as key intermediates in a number of domino reactions to construct heterocyclic systems [31-42]. However, a survey of literature reveals that a Povarov reaction with in situ generated $\beta$-enamino ester as dienophile has not been reported until now. Recently, Zhu and Masson successfully developed three-component Povarov reactions 
using enamides as dienophiles leading to a highly efficient synthesis of enantiomerically enriched 4-amino-tetrahydroquinolines $[43,44]$. In this work our aim is to describe the domino Povarov reaction with both in situ formed aldimine and in situ generated $\beta$-enamino ester for the facile synthesis of the functionalized tetrahydroquinoline.

\section{Results and Discussion}

It is known that the formation of $\beta$-enamino ester by the reaction of arylamine with methyl propiolate requires a relative long time [38-42]. Thus, under our previously established reaction conditions a molar excess of $p$-toludine $(4.0 \mathrm{mmol})$ and methyl propiolate $(2.0 \mathrm{mmol})$ reacted in ethanol at room temperature overnight to give the desired $\beta$-enamino ester. Then, benzaldehyde and $p$-toluenesulfonic acid was introduced in the reaction system and the sequential reaction was finished in 48 hours at room temperature monitored by TLC. After workup we were pleased to find that the functionalized tetrahydroquinoline 1c was prepared in $63 \%$ yield (Scheme 1). The tetrahydroquinoline was obviously formed by the reaction of the previously formed $\beta$-enamino ester with in situ generated $N$-aryl aldimine. Thus, a domino Povarov reaction is successfully established. Similarly, various arylamines and aromatic aldehydes were used in the reaction under the same conditions. The results are summarized in Table 1. All the reactions proceeded smoothly to afford the corresponding functionalized tetrahydroquinolines $(\mathbf{1 a}-\mathbf{1 m})$ in moderate to good yields (41-67\%). Arylamines and aromatic aldehydes with an electron-donating alkyl or methoxy group and with weak electron-withdrawing chloro or bromo groups reacted efficiently to give the expected products.<smiles>[R]c1ccc(N[C@H]2c3ccccc3N[C@H](c3ccc([R])cc3)[C@H]2C(C)=O)cc1</smiles>
1a-1m

Scheme 1: Synthesis of polysubstituted tetrahydroquinolines $1 \mathrm{a}-1 \mathrm{~m}$.

The structures of the above-prepared functionalized tetrahydroquinolines 1a-1 m were characterized by ${ }^{1} \mathrm{H}$ and ${ }^{13} \mathrm{C} \mathrm{NMR}$, MS, HRMS and IR spectra and were further confirmed by singlecrystal X-ray diffraction performed for the compound 1c (Figure 1). The ${ }^{1} \mathrm{H}$ NMR spectra of compounds 1a-1m usually show two doublets and one triplet shift for the three cyclic $\mathrm{CH}$ units at the tetrahydroquinoline core. For example, in the ${ }^{1} \mathrm{H}$ NMR spectrum of $1 \mathrm{a}$ the triplet at $3.09 \mathrm{ppm}$ belongs to the proton at the 3-position, while the doublets at 4.76 and
Table 1: Synthesis of the polysubstituted tetrahydroquinolines $1 \mathrm{a}-1 \mathrm{~m}$.

\begin{tabular}{lllll} 
Entry & Compound & $\mathrm{R}$ & $\mathrm{R}^{\prime}$ & Yield (\%) \\
\hline 1 & $\mathbf{1 a}$ & $\mathrm{H}$ & $\mathrm{H}$ & 64 \\
2 & $\mathbf{1 b}$ & $\mathrm{H}$ & $p-\mathrm{Cl}$ & 48 \\
3 & $\mathbf{1 c}$ & $p-\mathrm{CH}_{3}$ & $\mathrm{H}$ & 63 \\
4 & $\mathbf{1 d}$ & $p-\mathrm{CH}_{3}$ & $p-\mathrm{CH}_{3} \mathrm{O}$ & 46 \\
5 & $\mathbf{1 e}$ & $p-\mathrm{CH}_{3}$ & $p-\mathrm{CH}\left(\mathrm{CH}_{3}\right)_{2}$ & 41 \\
6 & $\mathbf{1 f}$ & $p-\mathrm{CH}_{3}$ & $p-\mathrm{Cl}$ & 48 \\
7 & $\mathbf{1 g}$ & $p-\mathrm{CH}_{3} \mathrm{O}$ & $p-\mathrm{CH}_{3}$ & 51 \\
8 & $\mathbf{1 h}$ & $p-\mathrm{Cl}$ & $\mathrm{H}$ & 59 \\
9 & $\mathbf{1 i}$ & $p-\mathrm{Cl}$ & $p-\mathrm{CH}_{3}$ & 66 \\
10 & $\mathbf{1 j}$ & $p-\mathrm{Cl}$ & $p-\mathrm{CH}_{3} \mathrm{O}$ & 54 \\
11 & $\mathbf{1 k}$ & $p-\mathrm{Cl}$ & $p-\mathrm{Cl}_{1}$ & 61 \\
12 & $\mathbf{1 l}$ & $p-\mathrm{Br}$ & $\mathrm{H}$ & 67 \\
13 & $\mathbf{1 m}$ & $p-\mathrm{Br}$ & $p-\mathrm{CH}_{3}$ & 56
\end{tabular}

$5.24 \mathrm{ppm}$ are clearly the protons at the 2- and 4-position. The three groups at the 2-, 3- and 4-position of tetrahydroquinoline could be of either cis or trans configuration. Thus, several diastereoisomers would exist in tetrahydroquinolines $\mathbf{1 a - 1} \mathbf{m}$. ${ }^{1} \mathrm{H}$ NMR spectra clearly indicates that there is only one diastereoisomer in the compounds $\mathbf{1 a}-\mathbf{1 m}$. Single crystal structure of compound 1c (Figure 1) clearly showed that three groups at the 2-, 3- and 4-positions exist in trans-configuration. Thus, by analyzing ${ }^{1} \mathrm{H}$ NMR spectra and the single crystal structure we could conclude that the prepared tetrahydroquinolines $\mathbf{1 a - 1 m}$ exist in (2,3)-trans-(3,4)-trans-configuration, which also means that this domino Povarov reaction is a highly stereoselective reaction.

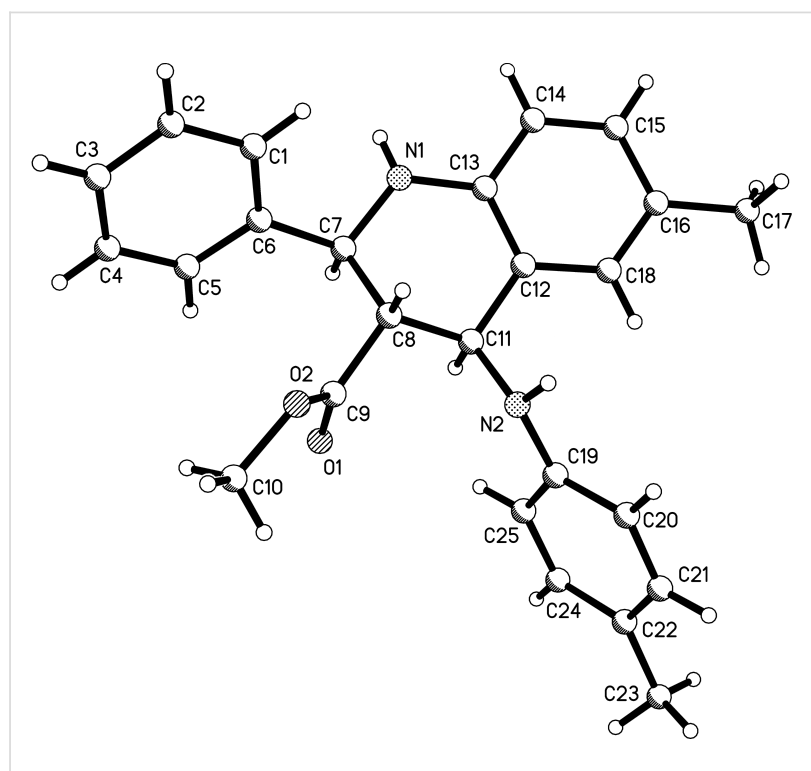

Figure 1: Molecular structure of compound 1c. 
<smiles>[R][R]1cccc(C=O)c1</smiles><smiles>[R]c1cccc(N/C=C/C(=O)OC)c1</smiles>
A<smiles>[R][R]1ccc(/C=N/c2ccc([R])cc2)cc1</smiles>

B<smiles>[R]c1ccc([C@H]2Nc3ccccc3C(Nc3cccc([R])c3)[C@H]2C(=O)OC)cc1</smiles>

1

Scheme 2: The proposed mechanism of domino Povarov reaction.

A reaction mechanism for this domino Povarov reaction is briefly outlined in Scheme 2 based on the published domino Povarov reaction [45-49]. At first, arylamine adds to methyl propiolate to form the $\beta$-enamino ester A. Secondly, excess arylamine reacts with the aromatic aldehyde to form the $N$-aryl aldimine $\mathbf{B}$ in the presence of $p$-toluenesulfonic acid as catalyst. Thirdly, the Mannich type addition of intermediate $\mathbf{A}$ with the acid-promoted $N$-aryl aldimine $\mathbf{B}$ gives the intermediate $\mathbf{C}$. Lastly, the intramolecular electrophilic aromatic substitution at the ortho position of the activated $N$-aryl ring gives the final

tetrahydroquinoline $\mathbf{1}$. On the other hand, the concerted imineDiels-Alder reaction of $N$-aryl aldimine $\mathbf{B}$ as the $N$-hetero diene with $\beta$-enamino ester $\mathbf{A}$ as the dienophile may give directly the tetrahydroquinoline $\mathbf{1}$. At present it is very difficult to distinguish these two reaction paths. It may be due to the fact that the four sequential reactions are all retro equilibrium reactions; the thermodynamically stable trans-isomer is obtained as the final separated product.

In the reaction mechanism shown in Scheme 2, arylamine reacts not only with methyl propiolate to form a $\beta$-enamino ester, but it also reacts with an aromatic aldehyde to form an imine. We envisioned that two kinds of aryl amines could be used in the reaction to give more polysubstituted tetrahydroquinolines. Thus, after the addition reaction of one kind of arylamine with methyl propiolate had been completed, the aromatic aldehyde and the second arylamine were introduced to the reaction system. By using this method the functionalized tetrahydroquinolines $\mathbf{2 a}-\mathbf{2 e}$ were successfully obtained in good yields (Table 2). This result showed that this domino Povarov reaction has a broad substrate scope.

\section{Conclusion}

In summary we investigated the domino three-component reaction of aromatic aldehydes, arylamines and methyl propiolates, and successfully established the imino Diels-Alder reaction with $\beta$-enamino ester as dienophile. This reaction provides a convenient and stereoselective procedure for the preparation of 2-aryl-4-arylamino-1,2,3,4-tetrahydroquinoline-3-carboxylates in satisfactory yields. Furthermore, we successfully developed the domino Povarov reaction with in situ generated $\beta$-enamino ester as dienophiles. This methodology is potentially useful in the synthesis of tetrahydroquinoline derivatives.

Table 2: Synthesis of functionalized tetrahydroquinolines $\mathbf{2 a}-\mathbf{2 e}$.

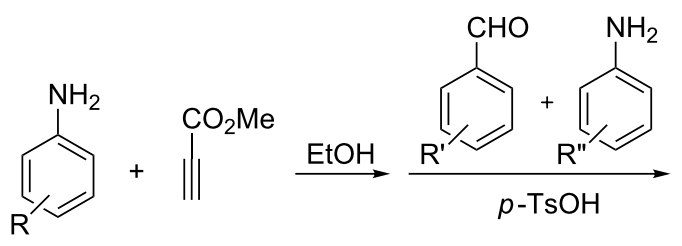<smiles>[R]c1ccc(NC2c3ccccc3NC(c3ccc([R])cc3)C2C(C)=O)cc1</smiles>

$2 a-2 e$

\begin{tabular}{|c|c|c|c|c|c|}
\hline Entry & Compound & $\mathrm{R}$ & $\mathrm{R}^{\prime}$ & R" & Yield (\%) \\
\hline 1 & $2 a$ & $p-\mathrm{CH}_{3}$ & $p-\mathrm{Cl}$ & $p-\mathrm{Cl}$ & 60 \\
\hline 2 & $2 b$ & $p-\mathrm{CH}_{3} \mathrm{O}$ & $p-\mathrm{Cl}$ & $p-\mathrm{Cl}$ & 63 \\
\hline 3 & $2 c$ & $p-\mathrm{CH}_{3}$ & $p-\mathrm{Cl}$ & $\mathrm{H}$ & 56 \\
\hline 4 & $2 d$ & $p-\mathrm{CH}_{3} \mathrm{O}$ & $p-\mathrm{Br}$ & $p-\mathrm{Cl}$ & 57 \\
\hline 5 & $2 e$ & $p-\mathrm{CH}_{3}$ & $m-\mathrm{CH}_{3}$ & $p-\mathrm{Cl}$ & 55 \\
\hline
\end{tabular}




\section{Experimental}

Reagents and apparatus. All reactions were monitored by TLC. Melting points were taken on a hot-plate microscope apparatus. IR spectra were obtained on a Bruker Tensor 27 spectrometer ( $\mathrm{KBr}$ disc). NMR spectra were recorded with a Bruker AV-600 spectrometer with $\mathrm{CDCl}_{3}$ as solvent and TMS as internal standard (600 and $150 \mathrm{MHz}$ for ${ }^{1} \mathrm{H}$ and ${ }^{13} \mathrm{C} \mathrm{NMR}$ spectra, respectively). HPLC/MS were measured on a Fennigan LCQ Deca XP MAX instrument. High-resolution mass (ESI) were obtained with a Bruker MicroTOF spectrometer. X-ray data were collected on a Bruker Smart APEX-2 CCD diffractometer. Aromatic aldehydes, arylamines, methyl propiolate and other reagents were commercial reagents and used as received. Solvents were purified by standard techniques.

General procedure for the synthesis of polysubstituted tetrahydroquinolines. A solution of arylamine $(4.0 \mathrm{mmol})$ and methyl propiolate $(2.0 \mathrm{mmol}, 0.168 \mathrm{~g})$ in $5 \mathrm{~mL}$ ethanol was stirred at room temperature overnight. Then, the aromatic aldehyde $(2.0 \mathrm{mmol})$ and $p$-toluenelsulfonic acid $(0.5 \mathrm{mmol})$ were added. The mixture was stirred at room temperature for an additional $48 \mathrm{~h}$. The resulting precipitate was collected and washed with cold ethanol to give the solid product, which was subjected to thin-layer chromatography with light petroleum and ethyl acetate $(\mathrm{v} / \mathrm{v}, 10: 1)$ as developing reagent to give the pure product for analysis.

\section{Supporting Information}

Experimental details and detailed spectroscopic data including crystallographic data (CIF) of all new compounds are available as Supporting Information. Single crystal data for compound 1c (CCDC 890916) have been deposited in the Cambridge Crystallographic Data Centre, 12 Union Road, Cambridge, CB2 1EZ, UK (Fax: +44-1223-336033; e-mail: deposit@ccdc.cam.ac.uk orwww: http://www.ccdc.cam.ac.uk).

\section{Supporting Information File 1}

General experimental methods and characterization of compounds.

[http://www.beilstein-journals.org/bjoc/content/ supplementary/1860-5397-8-211-S1.pdf]

\section{Supporting Information File 2}

$\mathrm{X}$-ray crystallographic data of $\mathbf{1 c}$.

[http://www.beilstein-journals.org/bjoc/content/ supplementary/1860-5397-8-211-S2.cif]

\section{Acknowledgements}

This work was financially supported by the National Natural Science Foundation of China (Grant No. 21172189) and the Priority Academic Program Development of Jiangsu Higher Education Institutions.

\section{References}

1. Nicolaou, K. C.; Snyder, S. A.; Montagnon, T.; Vassilikogiannakis, G. Angew. Chem., Int. Ed. 2002, 41, 1668. doi:10.1002/1521-3773(20020517)41:10<1668::AID-ANIE1668>3.0.CO ;2-Z

2. Takao, K.-i.; Munakata, R.; Tadano, K.-i. Chem. Rev. 2005, 105, 4779 doi:10.1021/cr040632u

3. Reymond, S.; Cossy, J. Chem. Rev. 2008, 108, 5359. doi:10.1021/cr078346g

4. Schmidt, R. R. Acc. Chem. Res. 1986, 19, 250. doi:10.1021/ar00128a004

5. Weinreb, S. M.; Scola, P. M. Chem. Rev. 1989, 89, 1525. doi:10.1021/cr00097a008

6. Tietze, L. F.; Kettschau, G. Top. Curr. Chem. 1997, 189, 1. doi:10.1007/BFb0119240

7. Yadav, J. S.; Reddy, B. V. S.; Madhuri, C. R.; Sabitha, G. Synthesis 2001, 1065. doi:10.1055/s-2001-14904

8. Pellissier, H. Tetrahedron 2009, 65, 2839. doi:10.1016/j.tet.2009.01.068

9. Kouznetsov, V. V. Tetrahedron 2009, 65, 2721. doi:10.1016/j.tet.2008.12.059

10. Choudhury, L. H.; Parvin, T. Tetrahedron 2011, 67, 8213. doi:10.1016/j.tet.2011.07.020

11. Majumdar, K. C.; Taher, A.; Nandi, R. K. Tetrahedron 2012, 68, 5693. doi:10.1016/j.tet.2012.04.098

12. Palacios, A.; Herrán, E.; Alonso, C.; Rubiales, G. Tetrahedron 2006, 62, 7661. doi:10.1016/j.tet.2006.05.073

13. Alves, M. J.; Azoia, N. G.; Fortes, A. G. Tetrahedron 2007, 63, 727 doi:10.1016/j.tet.2006.10.085

14. Jin, G.; Zhao, J.; Han, J.; Zhu, S.; Zhang, J. Tetrahedron 2010, 66 913. doi:10.1016/j.tet.2009.11.092

15. Spanedda, M. V.; Hoang, V. D.; Crousse, B.; Bonnet-Delpon, D.; Bégué, J. P. Tetrahedron Lett. 2003, 44, 217. doi:10.1016/S0040-4039(02)02558-3

16. Maiti, G.; Kundu, P. Tetrahedron Lett. 2006, 47, 5733. doi:10.1016/j.tetlet.2006.06.034

17. Chen, Z.; Lin, L.; Chen, D.; Li, J.; Liu, X.; Feng, X. Tetrahedron Lett. 2010, 51, 3088. doi:10.1016/j.tetlet.2010.04.009

18. Rajanarendar, E.; Reddy, M. N.; Reddy, K. G.; Krishna, S. R. Tetrahedron Lett. 2012, 53, 2909. doi:10.1016/j.tetlet.2012.04.002

19. Kouznetsov, V. V.; Mora Cruz, U.; Zubkov, F. I.; Nikitina, E. V. Synthesis 2007, 375. doi:10.1055/s-2007-965875

20. Kouznestov, V. V.; Romero Bohórquez, A. R.; Astudillo Saavedra, L.; Fierro Medina, R. Mol. Diversity 2006, 10, 29. doi:10.1007/s11030-006-2344-8

21. Guinó, M.; Phua, P. H.; Caille, J.-C.; Hii, K. K. J. Org. Chem. 2007, 72, 6290. doi:10.1021/jo071031g

22. Katrizky, A. R.; Rachwal, B.; Rachwal, S. J. Org. Chem. 1995, 60, 3993. doi:10.1021/jo00118a014

23. Lue, P.; Greenhill, J. V. Adv. Heterocycl. Chem. 1996, 67, 207. doi:10.1016/S0065-2725(08)60072-0 
24. Elassara, A.-Z. A.; El-Khair, A. A. Tetrahedron 2003, 59, 8463. doi:10.1016/S0040-4020(03)01201-8

25. Bagley, M. C.; Dale, J. W.; Bower, J. Chem. Commun. 2002, 1682. doi:10.1039/b203900a

26. Valla, A.; Valla, B.; Cartier, D.; Le Guillou, R.; Labia, R.; Potier, P. Tetrahedron Lett. 2005, 46, 6671. doi:10.1016/j.tetlet.2005.07.141

27. Glotova, T. E.; Dvorko, M. Yu.; Ushakov, I. A.; Chipanina, N. N.; Kazheva, O. N.; Chekhlov, A. N.; Dyachenko, O. A.; Gusarova, N. K.; Trofimov, B. A. Tetrahedron 2009, 65, 9814. doi:10.1016/j.tet.2009.09.069

28. Ziyaei-Halimehjani, A.; Saidi, M. R. Tetrahedron Lett. 2008, 49, 1244-1248. doi:10.1016/j.tetlet.2007.12.042

29. Li, X.; Wang, J.-Y.; Yu, W.; Wu, L.-M. Tetrahedron 2009, 65, 1140. doi:10.1016/j.tet.2008.11.095

30. Yavari, I.; Bayat, M. J.; Sirouspour, M.; Souri, S. Tetrahedron 2010, 66, 7995. doi:10.1016/j.tet.2010.08.016

31. Srikrishna, A.; Sridharan, M.; Prasad, K. R. Tetrahedron 2010, 66, 3651. doi:10.1016/j.tet.2010.03.084

32. Bezenšek, J.; Koleša, T.; Grošelj, U.; Wagger, J.; Stare, K.; Meden, A.; Svete, J.; Stanovnik, B. Tetrahedron Lett. 2010, 51, 3392. doi:10.1016/j.tetlet.2010.04.106

33. Alizadeh, A.; Rostamnia, S.; Zohreh, N.; Hosseinpour, R. Tetrahedron Lett. 2009, 50, 1533. doi:10.1016/j.tetlet.2008.12.107

34. Cao, H.; Jiang, H.-F.; Qi, C.-R.; Yao, W.-J.; Chen, H.-J. Tetrahedron Lett. 2009, 50, 1209. doi:10.1016/j.tetlet.2009.01.002

35. Liu, W.-B.; Jiang, H.-F.; Zhu, S.-F.; Wang, W. Tetrahedron 2009, 65, 7985. doi:10.1016/j.tet.2009.07.046

36. Jiang, H.-F.; Li, J.-H.; Chen, Z.-W. Tetrahedron 2010, 66, 9721. doi:10.1016/j.tet.2010.10.041

37. Zhu, Q.; Jiang, H.; Li, J.; Liu, S.; Xia, C.; Zhang, M. J. Comb. Chem. 2009, 11, 685. doi:10.1021/cc900046f

38. Sun, J.; Xia, E.-Y.; Wu, Q.; Yan, C.-G. Org. Lett. 2010, 12, 3678. doi:10.1021/ol101475b

39. Sun, J.; Wu, Q.; Xia, E. Y.; Yan, C.-G. Eur. J. Org. Chem. 2011, 2981. doi:10.1002/ejoc.201100008

40.Sun, J.; Xia, E.-Y.; Wu, Q.; Yan, C.-G. ACS Comb. Sci. 2011, 13, 421. doi:10.1021/co200045t

41. Sun, J.; Sun, Y.; Xia, E.-Y.; Yan, C.-G. ACS Comb. Sci. 2011, 13, 436. doi:10.1021/co200071v

42. Sun, J.; Sun, Y.; Gao, H.; Yan, C.-G. Synthesis 2012, 1069. doi:10.1055/s-0031-1289718

43. Liu, H.; Dagousset, G.; Masson, G.; Retailleau, P.; Zhu, J. J. Am. Chem. Soc. 2009, 131, 4598. doi:10.1021/ja900806q

44. Dagousset, G.; Zhu, J.; Masson, G. J. Am. Chem. Soc. 2011, 133, 14804. doi:10.1021/ja205891m

45. Zhang, W.; Guo, Y.; Liu, Z.; Jin, X.; Yang, L.; Liu, Z.-L. Tetrahedron 2005, 61, 1325. doi:10.1016/j.tet.2004.11.042

46. Zhou, Y.; Jia, X.; Li, R.; Liu, Z.; Liu, Z.; Wu, L. Tetrahedron Lett. 2005, 46, 8937. doi:10.1016/j.tetlet.2005.10.083

47. Han, B.; Jia, X.-D.; Jin, X.-L.; Zhou, Y.-L.; Yang, L.; Liu, Z.-L.; Yu, W. Tetrahedron Lett. 2006, 47, 3545. doi:10.1016/j.tetlet.2006.03.083

48. Savitha, G.; Perumal, P. T. Tetrahedron Lett. 2006, 47, 3589. doi:10.1016/j.tetlet.2006.03.046

49. Nomura, Y.; Kimura, M.; Takeuchi, Y.; Tomoda, S. Chem. Lett. 1978, 267. doi:10.1246/cl.1978.267

\section{License and Terms}

This is an Open Access article under the terms of the Creative Commons Attribution License

(http://creativecommons.org/licenses/by/2.0), which permits unrestricted use, distribution, and reproduction in any medium, provided the original work is properly cited.

The license is subject to the Beilstein Journal of Organic Chemistry terms and conditions:

(http://www.beilstein-journals.org/bjoc)

The definitive version of this article is the electronic one which can be found at:

doi:10.3762/bjoc.8.211 